\title{
Term Structure Estimation in Low-Frequency Transaction Markets: A Kalman Filter Approach with Incomplete Panel-Data
}

\author{
GONZALO CORTAZAR \\ Pontificia Universidad Católica de Chile \\ EDUARDO S. SCHWARTZ \\ University of California at Los Angeles \\ LORENZO NARANJO \\ Pontificia Universidad Católica de Chile
}

March 2003 


\begin{abstract}
There are two issues that are of central importance in term structure analysis. One is the modeling and estimation of the current term structure of spot rates. The second is the modeling and estimation of the dynamics of the term structure. These two issues have been addressed independently in the literature. The methods that have been proposed assume a sufficiently complete price data set and are generally implemented separately. However, when the methods are applied to markets with sparse bond price, results are unsatisfactory.

We develop a method for jointly estimating the current term structure and its dynamics for markets with low-frequency transactions. We propose solving both issues by using a dynamic term structure model estimated from incomplete panel data. To achieve this, we modify the standard Kalman filter approach to deal with the missing-observation problem. In this way, we can use historic price data in a dynamic model to estimate the current term structure. With this approach we are able to obtain an estimate of the current term structure even for days with an arbitrary low number of price observations.

The proposed methodology can be applied to a broad class of continuous-time term-structure models with any number of stochastic factors. To show the implementation of the approach, we estimate a three-factor generalizedVasicek model using Chilean government bond price data. The approach, however, may be used in any market with low-frequency transactions, a common characteristic of many emerging markets.
\end{abstract}




\section{Introduction}

There are two issues that are of central importance in term structure analysis. One is the modeling and estimation of the current term structure of spot rates, which is essential for valuing and hedging cash flows that are linearly related to the discount function. The second is the modeling and estimation of the dynamics of the term structure, which is indispensable for valuing and hedging cash flows that are non-linear functions of the term structure (all types of options). These two issues have been addressed independently in the literature.

On one hand, for current term-structure estimation, most authors have proposed parametric and nonparametric methods for fitting curves to current bond prices (or yields) without regard to past prices. McCulloch (1971, 1975), Vasicek and Fong (1982), and Fisher, Nychka and Zervos (1994), among others, use spline curve-fitting methods to estimate the current term structure. Nelson and Siegel (1987), and Svensson (1994) use parsimonious representations of the yield curve, limiting the number of parameters and giving more stability to the term structure.

On the other hand, in the modeling of the term structure dynamics the main concern is the movement of the term structure across time. To address this issue one alternative is to model the stochastic movement of the spot rate and then to use no-arbitrage arguments to infer the dynamics of the term structure. Examples of this approach include one-factor mean-reverting models [Vasicek (1977)], two-factor models [Brennan and Schwartz (1979)], multifactor extensions of the Vasicek model [Langetieg (1980)], single-factor general equilibrium models [Cox, Ingersoll and Ross (1985)] and multi-factor extensions of the CIR model [Duffie and Kan (1996)], among many others.

An alternative approach to model the dynamics of the term-structure is to use the whole current term structure as the input of the model and no-arbitrage arguments to infer its stochastic movement [Ho and Lee (1986), Heath, Jarrow and Morton (1992)]. These type of models use all the information contained in the current term structure, but are more difficult to implement than the previous ones.

Once a dynamic model of interest rates is proposed, the estimation method that will be used must be chosen. One possibility is to estimate the model 
using a time-series of bond prices [Chan, Karolyi, Longstaff, and Sanders (1992), Broze, Scaillet, and Zakoian (1995), Brenner, Harjes, and Kroner (1996), Nowman (1997, 1998), Andersen and Lund (1997)]. Alternatively, state variables and parameters may be estimated from a panel of bond prices with different maturities [Chen and Scott (1993), Pearson and Sun (1994), and Duffie and Singleton (1997)].

Even though there are obvious benefits of calibrating a model using a panel with a large number of price observations, the richer the data set, the larger the estimated measurement errors. These errors arise from the inability of a model with a limited number of factors to perfectly explain a large number of contemporaneous prices. A powerful and widely used methodology to optimally estimate unobservable state variables from a noisy panel-data is the Kalman filter. Recent applications of this methodology to dynamic models of interest rates include Lund (1994, 1997), Duan and Simonato (1995), Ball and Torous (1996), Geyer and Pichler (1998), Babbs and Nowman (2001), and Chen and Scott (2003). The advantage of using the Kalman filter on a panel-data is that it jointly uses all present and past price information to estimate the current term structure. Maximum likelihood methods can then be used to estimate the parameters of the model.

Both type of methods proposed in the literature, curve-fitting for estimating the current term structure and Kalman filtering for dynamic models, have been successfully applied to markets for which there is a sufficiently complete price data-set. However, when these methods are used in markets with sparse bond price data, results become unsatisfactory. For example, traditional curve-fitting methods render unreliable estimates of the current term structure for days without a sufficient number of observations or without short or long-term bond prices. In addition, a typical Kalman filter implementation assumes a complete panel of bond prices (or yields), which becomes problematic if there is a substantial number of missing observations as is the case in many emerging markets.

In this work, we develop a method to jointly estimate the current term structure and its dynamics for markets with low-frequency transactions. We propose solving both issues by using a dynamic term structure model estimated from incomplete panel data. To achieve this, we modify the standard Kalman filter approach to deal with the missing-observation problem. We can then use historical price data and a dynamic model to estimate the current term structure. With this 
approach, we are able to obtain an estimate of the current term structure even for days with an arbitrary low number of price observations.

The proposed methodology can be applied to a broad class of continuous-time term-structure models with any number of stochastic factors. To show the implementation of the approach, we estimate a three-factor generalizedVasicek model using Chilean government bond price data. The approach, however, may be used in any market with low-frequency transactions, a common characteristic of many emerging markets.

The next section explains the shortcomings of static term-structure estimation methods when there are sparse data. In Section 3 we present the generalized Vasicek model that will be used for illustrating our methodology. Section 4 presents the standard Kalman filter method and shows how it can be used in an incomplete panel-data setting. Section 5 presents empirical results of applying the methodology to the Chilean government bond market and Section 6 concludes.

\section{Shortcomings of Static Term-Structure Estimation in Low- Frequency Transaction Markets}

Term structure estimation has been traditionally implemented with static models that only use current bond prices (or yields), without regard to past information. Some methods, like Nelson and Siegel (1987) and Svensson (1994), assume a parametric functional form for the forward rates ${ }^{1}$. Other methods, for example McCulloch (1971, 1975), and Fisher, Nychka and Zervos (1994), use nonparametric spline-based interpolation methods to calculate the term structure. Empirical evidence shows that in well developed markets, where numerous bonds are traded every day for different maturities, these static methods generate yield curves that accurately fit current bond transactions [Bliss (1996)].

There are, however, other features besides goodness-of-fit to observed prices that are desirable in a term-structure model, such as the time-series stability of

\footnotetext{
${ }^{1}$ See Appendix A for details on these methods.
} 
the term-structure curves obtained. This stability can be analyzed by observing the sequence of daily term-structure estimations implied by the model. It might well be the case that the model fits very well existing bond prices (or yields), but it implies large daily movements of yields for maturities that are not traded. This is not an issue for liquid markets, but as we shall see, is a mayor problem for thin markets. To assess the stability of the term-structure curves obtained, we can compare the term structure of volatilities from the model with actual volatility from the data. ${ }^{2}$

In markets with a complete cross-section of prices for each date, volatility of interest rates computed from the estimated term structures will perfectly match historical data and the stability of the model is not an issue. However, for sparse data sets in which at each date there are only a few different bond maturities traded, stability will become an important criteria for judging the reliability of the term structure estimation. In what follows we show that term-structure models that use only current bond prices may be unreliable judged on the basis of the instability of the term-structure estimates.

One cause for the instability of curve-fitting estimates of the termstructure in low-frequency transactions markets is the reduced number of daily transactions, which makes it difficult to have robust estimations. When the number of prices for a particular date is close to the number of parameters to be estimated, any measurement error crucially affects the shape of the curve. Figure 1 illustrates an extreme (but not uncommon in emerging markets) case of a date with fewer prices than model parameters by plotting two of the infinite term-structures that perfectly explain observed prices. This case is taken from one of the many dates in the Chilean government bond market with extremely thin trading. Curve-fitting methods clearly cannot be applied to dates with very low number of transactions.

A second cause of instability of these static curve-fitting methods when used in low-frequency transactions markets is the unavailability of prices for short or for long-term bonds. Curve-fitting methods provide reasonable estimates within the time range spanned by the shortest and the longest maturity bond, but provide much less reliable estimates for extrapolations outside this time frame.

\footnotetext{
${ }^{2}$ In section 5 we will detail how to make this comparison.
} 
In many emerging markets it is common that for some dates long-term bonds are not traded; but the need for a complete term-structure estimation for valuation and hedging purposes remains. Figure 2 illustrates a 20-year termstructure estimate of the coupon-bond-yield in Chile for a date in which the longestmaturity bond traded was only 6 years. Given the low number of transactions of Chilean government inflation-protected bonds ${ }^{3}$ on 10/06/1999, we use all purediscount and coupon bonds traded on that date to compute the implied pure-discount yield curve using the Svensson (1994) method. Once this curve is obtained we infer the yields of coupon bonds with maturities from 0.5 to 20 years priced using the implied pure-discount yield curve estimated earlier. This coupon-yield curve is then plotted in Figure 2 together with the yields of all market transactions on 10/06/1999 and on the day before.

From Figure 2 we can see that prices of traded bonds with similar maturities did not change much between both dates and that long-term bonds were traded only on the first day. Even though observed prices indicate that markets seem to have behaved similarly on both dates, the model estimates a difference of almost $1 \%$ in the yield of a 19-year coupon-bond. This is difficult to justify. Curve-fitting methods seem to provide unstable estimates of long rates when no long-term bonds are traded.

Instability of term-structure estimates can be measured by comparing the model's volatility term-structure with the empirical behavior of interest rates. It is a well-known fact that the term structure of interest rates exhibits mean reversion, which implies a downward-slopping volatility term-structure. This means that the volatility of long rates should be lower than the volatility of short rates.

Figure 3 plots the volatility of interest rates calculated from daily estimations of the term-structure in Chile between 1997 and 2001 using the Svensson (1994) method. It can be seen that this term-structure of volatilities is not consistent with mean reversion in interest rates: it implies very high volatilities for long-rates. Moreover, the Svensson volatility estimates are much higher than the empirical

\footnotetext{
${ }^{3}$ The coupon bonds considered here are amortizing bonds paying semi-annually equal coupons. These instruments are described in more detail in Section 5.
} 
estimates obtained directly from bond prices suggesting that missing observations induce unreliable rate estimates. Similar results are obtained when using other curve-fitting methods like Nelson and Siegel (1987). This is confirmed by Molinare (2002), who finds that these static curve-fitting methods are reliable only with relatively complete cross-sections of data.

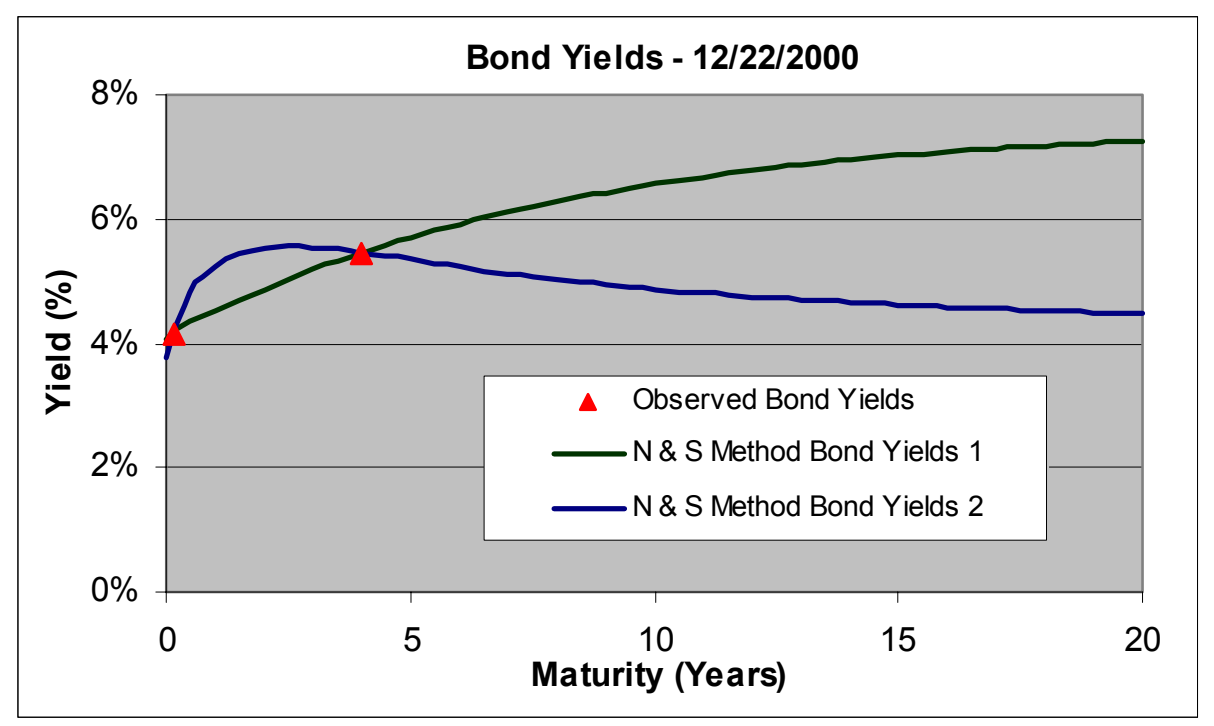

Fig. 1. Two different estimations of yield curves from Chilean government inflationprotected discount and coupon bond data using the Nelson \& Siegel method for $12 / 22 / 2000$. 


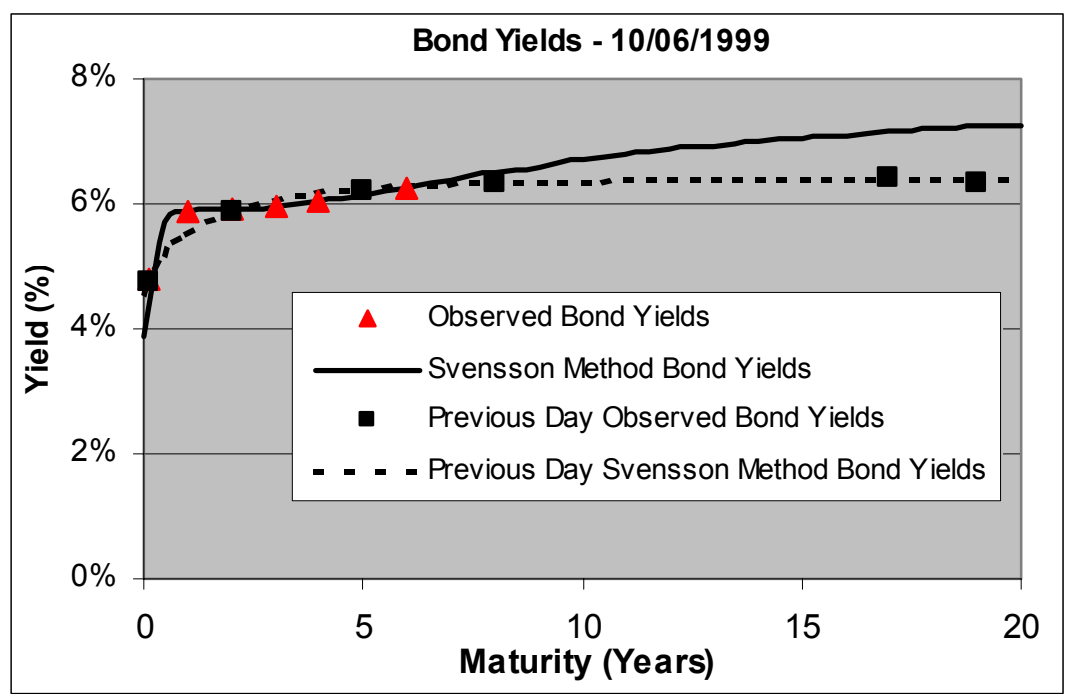

Fig. 2. Coupon bond yields for two consecutive dates (10/05/1999 and 10/06/1999) estimated from Chilean government inflation-protected discount and coupon bond data using the Svensson (1994) method.

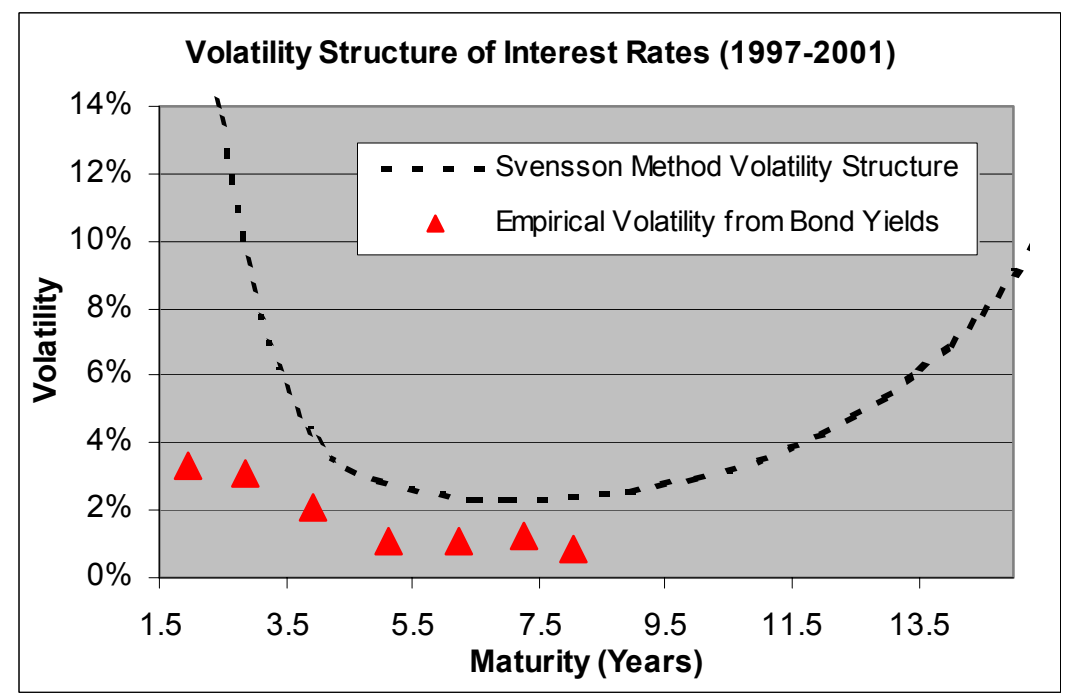

Fig. 3. Empirical volatilities of interest rates in Chile and volatilities obtained from daily estimations of the term-structure between 1997 and 2001 using the Svensson (1994) method. 


\section{The Generalized Vasicek Dynamic Term-Structure Model}

As was shown in the previous section, traditional static term structure estimation only incorporates current bond price (or yield) observations, without regard to past information. When long-term bond prices are not available, the estimation of long-term interest rates becomes unreliable. Also, in the absence of a sufficient number of transactions, an over-parameterization of traditional models can occur.

We propose to solve the problems of term-structure estimation in lowfrequency transaction markets, by using also past price information to infer the current term structure. This requires a dynamic model of the stochastic behavior of interest rates to be able to mix current and past prices in a meaningful way.

Some dynamic models, in particular multifactor ones, use a limited number of unobservable factors to summarize the stochastic behavior of the whole yield curve in a way that is sufficiently accurate, but also tractable. These unobservable state variables, together with the model parameters, must be estimated using observable bond price information. In the following sections we present an estimation methodology, based in the Kalman filter, that may be successfully used to estimate the term structure in low-frequency transaction markets. To illustrate our estimation methodology we will assume a generalized Vacisek model for the instantaneous risk free interest rate. Our methodology may be used, however, with other interest rate models such as a one factor CIR model [Cox, Ingersoll and Ross (1985)], a multifactor CIR model [Duffie and Kan (1996)] or general exponentialaffine models [Dai and Singleton (2001)], among others.

A generalized Vasicek model is a multifactor mean-reverting Gaussian model of the instantaneous spot interest rate which extends the classic Vasicek (1977). In Vasicek (1977) the interest rate follows an Ornstein-Uhlembeck process and therefore is assumed to revert to a long term rate.

The generalized Vasicek formulation goes back to Langetieg (1980), and is also analyzed in Babbs and Nowman (1999). It considers $n$ stochastic meanreverting factors represented by the vector $\mathbf{x}_{t}$, of dimension $n \times 1$, that define the instantaneous interest rate $r_{t}$ : 


$$
r_{t}=\mathbf{1}^{\prime} \mathbf{x}_{t}+\delta
$$

The vector of state variables $\mathbf{x}_{t}$ is governed by the following stochastic differential equation:

$$
d \mathbf{x}_{t}=-\mathbf{K} \mathbf{x}_{t} d t+\Sigma d \mathbf{w}_{t}
$$

where $\mathbf{K}=\operatorname{diag}\left(k_{i}\right)$ and $\boldsymbol{\Sigma}=\operatorname{diag}\left(\sigma_{i}\right)$ are $n \times n$ diagonal matrices with entries that are strictly positives constants and different. Also, $d \mathbf{w}_{t}$ is a $n \times 1$ vector of correlated Brownian motion increments such that:

$$
\left(d \mathbf{w}_{t}\right)^{\prime}\left(d \mathbf{w}_{t}\right)=\mathbf{\Omega} d t
$$

where the $(i, j)$ element of $\boldsymbol{\Omega}$ is $\rho_{i j} \in[1,-1]$, the instantaneous correlation of state variables $i$ and $j$. Under this specification, the state variables have the multivariate normal distribution and each of them reverts to 0 , at a mean reversion rate $^{4}$ given by $k_{i}$. Thus, according to equation (1) the instantaneous interest rate reverts to a long term value given by the constant $\delta$. Note that this is a canonical model in the sense that it contains the minimum number of parameters that can be econometrically identified (see Dai and Singleton, 2001) ${ }^{5}$.

By assuming a constant market price of risk $^{6} \lambda$, the risk-adjusted process for the vector of the state variables is:

$$
d \mathbf{x}_{t}=-\left(\boldsymbol{\lambda}+\mathbf{K} \mathbf{x}_{t}\right) d t+\boldsymbol{\Sigma} d \mathbf{w}_{t}
$$

4 In a mean reverting model, every perturbation is on average reduced by half in $\log (2) / k_{i}$ units of time.

${ }^{5}$ The canonical form proposed by Dai and Singleton (2001) for Gaussian interest rates allows for the possibility of common eigenvalues in matrix $\boldsymbol{K}$. To obtain simpler analytical formulas for the prices of pure discount bonds, we impose the condition that all eigenvalues are different, but this restriction may easily be relaxed.

${ }^{6} \mathrm{We}$ assume for simplicity that the market price of risk is constant, but this could be extended to any linear function of the state variables. 
where $\lambda$ is a $n \times 1$ vector of constants.

Applying standard no-arbitrage arguments, we obtain the value of a purediscount bond $P\left(r_{t}, t\right)$ :

$$
P\left(\mathbf{x}_{t}, \tau\right)=\exp \left(\mathbf{u}(\tau)^{\prime} \mathbf{x}_{t}+v(\tau)\right)
$$

where

$$
\begin{aligned}
u_{i}(\tau) & =-\frac{1-\exp \left(-k_{i} \tau\right)}{k_{i}} \\
v(\tau) & =\sum_{i=1}^{N} \frac{\lambda_{i}}{k_{i}}\left(\tau-\frac{1-\exp \left(-k_{i} \tau\right)}{k_{i}}\right)-\delta \cdot \tau \\
& +\frac{1}{2} \sum_{i=1}^{N} \sum_{j=1}^{N} \frac{\sigma_{i} \sigma_{j} \rho_{i j}}{k_{i} k_{j}}\left(\tau-\frac{1-\exp \left(-k_{i} \tau\right)}{k_{i}}-\frac{1-\exp \left(-k_{j} \tau\right)}{k_{j}}+\frac{1-\exp \left(-\left(k_{i}+k_{j}\right) \tau\right)}{k_{i}+k_{j}}\right)
\end{aligned}
$$

Sometimes it is convenient to work with the equivalent annualized spot rate. From equation (5) we obtain:

$$
R\left(\mathbf{x}_{t}, \tau\right)=-\frac{1}{\tau} \log P\left(\mathbf{x}_{t}, \tau\right)=-\frac{1}{\tau}\left(\mathbf{u}(\tau)^{\prime} \mathbf{x}_{t}+v(\tau)\right)
$$

which is a linear function of the state variables. Therefore, under the generalized Vasicek model, spot rates also have the Gaussian distribution.

The value of a coupon-bond $B\left(\mathbf{x}_{t}, t\right)$ with maturity $\tau=\tau_{N}$ and $N$ coupons $C_{i}$ paying at times $\tau_{i}$ can therefore be computed as:

$$
B\left(\mathbf{x}_{t}, \tau\right)=\sum_{i=1}^{N} C_{i} P\left(\mathbf{x}_{t}, \tau_{i}\right)
$$

The implied yield to maturity, $y\left(\mathbf{x}_{t}, \tau\right)$, of a coupon-bond maturing at $\tau$ is obtained solving the following equation:

$$
B\left(\mathbf{x}_{t}, \tau\right)=\sum_{i=1}^{N} C_{i} \exp \left(-y \tau_{i}\right)
$$


Note that if $C_{i} \geq 0, \forall i \in[1, N]$, the relationship between $B\left(\mathbf{x}_{t}, \tau\right)$ and $y\left(\mathbf{x}_{t}, \tau\right)$ is one-to-one and continuous in the state variables. However, unlike spot rates, $y\left(\mathbf{x}_{t}, \tau\right)$ is not a linear function of the state variables and will not distribute Normal.

\section{Kalman Filter Estimation with Incomplete Panel-Data}

The Kalman filter is a widely used methodology which recursively calculates optimal estimates of unobservable state variables, given all the information available up to some moment in time. Using Maximum Likelihood methods, we can also obtain consistent estimates of model parameters. In finance, the Kalman filter has been used to estimate and implement stochastic models of interest rates $^{7}$, commodities ${ }^{8}$ and other relevant economic variables ${ }^{9}$.

In spite of its extensive use, the literature has not stressed the Kalman filter's ability to use historical information when there are missing observations. Most previous work have used complete panel-data, even at the cost of throwing away data on contracts not traded frequently or of aggregating data with close to, but not identical, maturities, with evident loss of information ${ }^{10}$. This problem is particularly acute in low-frequency transaction markets where contracts with specific maturities do not trade every day.

Some authors, however, have applied Kalman filter for incomplete paneldata in commodity markets [Cortazar and Naranjo (2003), Naranjo (2002) and

${ }^{7}$ For example see Lund (1994, 1997), Duan and Simonato (1995), Geyer and Pichler (1998), Babbs and Nowman (1999), de Jong and Santa-Clara (1999), and de Jong (2000).

${ }^{8}$ For example see Schwartz (1997), Schwartz and Smith (2000), and Sørensen (2002)

${ }^{9}$ See for example Pennacchi (1991), and Dewachter and Maes (2001).

${ }^{10}$ Cortazar and Schwartz (2003) discuss this issue and propose an alternative approach that does not use the Kalman Filter to deal with this problem of missing observations and apply it to commodity futures. 
Sørensen (2002)]. We will show that a natural extension of the standard Kalman filter may be applied to jointly estimate the current term structure and its dynamics when working in low-frequency transaction markets.

\subsection{Standard Kalman Filter}

In this section we present a very general description of the Kalman filter. For a detailed explanation, see for example Harvey (1989), Chapter 3 or Hamilton (1994), Chapter 13.

The Kalman filter may be applied to dynamic models that are in a statespace representation, which include measurement and transition equations. At each point in time, the measurement equation relates a vector of observable variables $\mathbf{z}_{t}$ with a vector of state variables $\mathbf{x}_{t}$, which in general is not observable:

$$
\mathbf{z}_{t}=\mathbf{H}_{t} \mathbf{x}_{t}+\mathbf{d}_{t}+\mathbf{v}_{t} \quad \mathbf{v}_{t} \sim N\left(\mathbf{0}, \mathbf{R}_{t}\right)
$$

where $\mathbf{z}_{t}$ is a $m \times 1$ vector, $\mathbf{H}_{t}$ is a $m \times n$ matrix, $\mathbf{x}_{t}$ is a $n \times 1$ vector, $\mathbf{d}_{t}$ is a $m \times 1$ vector and $\mathbf{v}_{t}$ is a $m \times 1$ vector of serially uncorrelated Gaussian disturbances with mean $\mathbf{0}$ and covariance matrix $\mathbf{R}_{t}$. Even though we have implicitly assumed that vector $\mathbf{z}_{t}$ of observable variables is of a fixed size, we will later relax this assumption to allow for missing observations. Also, note that the measurement equation contains a disturbance term to allow for measurement errors in the observed data. Measurement equation (11) also assumes the existence of a linear relation between observed variables and state variables, assumption that later will also be relaxed.

The transition equation describes the dynamics of the state variables:

$$
\mathbf{x}_{t}=\mathbf{A}_{t} \mathbf{x}_{t-1}+\mathbf{c}_{t}+\boldsymbol{\varepsilon}_{t} \quad \boldsymbol{\varepsilon}_{t} \sim N\left(\mathbf{0}, \mathbf{Q}_{t}\right)
$$

where $\mathbf{A}_{t}$ is a $n \times n$ matrix, $\mathbf{c}_{t}$ is an $n \times 1$ vector and $\boldsymbol{\varepsilon}_{t}$ is an $n \times 1$ vector of serially uncorrelated Gaussian disturbances with mean $\mathbf{0}$ and covariance matrix $\mathbf{Q}_{t}$.Under this representation, the state variables have a multivariate Normal distribution. This assumption can also be relaxed to include non-Gaussian models for the state 
variables. Equations (11) and (12) define what is called the state space representation ${ }^{11}$.

The Kalman filter provides optimal estimates $\hat{\mathbf{x}}_{t}$ of the state variables given all the information up to time $t$. Let $\mathbf{P}_{t}$ be the covariance matrix of the estimation errors:

$$
\mathbf{P}_{t}=\mathrm{E}\left(\mathbf{x}_{t}-\hat{\mathbf{x}}_{t}\right)\left(\mathbf{x}_{t}-\hat{\mathbf{x}}_{t}\right)^{T}
$$

Then, given $\hat{\mathbf{x}}_{t-1}$ and $\mathbf{P}_{t-1}$, which include all the information up to time $t-1$, the estimator of the state variables and the covariance matrix of the estimation errors at time $\mathrm{t}$ are:

$$
\begin{aligned}
& \hat{\mathbf{x}}_{t \mid t-1}=\mathbf{A}_{t} \hat{\mathbf{x}}_{t-1}+\mathbf{c}_{t} \\
& \mathbf{P}_{t \mid t-1}=\mathbf{A}_{t} \mathbf{P}_{t-1} \mathbf{A}_{t}^{\prime}+\mathbf{Q}_{t}
\end{aligned}
$$

Equations (14) and (15) are usually called the prediction step.

When new information (represented by $\mathbf{z}_{t}$ ) is available, it is used to obtain an optimal estimate of the state variables and of the error covariance matrix:

$$
\begin{aligned}
& \hat{\mathbf{x}}_{t}=\hat{\mathbf{x}}_{t \mid t-1}+\mathbf{P}_{t \mid t-1} \mathbf{H}_{t}^{\prime} \mathbf{F}_{t}^{-1} \mathbf{v}_{t} \\
& \mathbf{P}_{t}=\mathbf{P}_{t \mid t-1}-\mathbf{P}_{t \mid t-1} \mathbf{H}_{t}^{\prime} \mathbf{F}_{t}^{-1} \mathbf{H}_{t} \mathbf{P}_{t \mid t-1}
\end{aligned}
$$

where

$$
\begin{aligned}
& \mathbf{F}_{t}=\mathbf{H}_{t} \mathbf{P}_{t \mid t-1} \mathbf{H}_{t}^{\prime}+\mathbf{R}_{t} \\
& \mathbf{v}_{t}=\mathbf{z}_{t}-\left(\mathbf{H}_{t} \hat{\mathbf{x}}_{t \mid t-1}+\mathbf{d}_{t}\right)
\end{aligned}
$$

Equations (16) and (17) correspond to what is usually called the update step.

\footnotetext{
${ }^{11}$ The state space representation of the generalized Vasicek model is described in detail
} in Appendix B. 
Intuitively, the update step is just the calculation of the conditional expectation of state variables $\mathbf{x}_{t}$, given all the history of observations $\left\{\mathbf{z}_{t}\right\}_{t=1}^{t-1}$, and the new information $\mathbf{z}_{\mathbf{t}}$, i.e. $\hat{\mathbf{x}}_{t}=\mathrm{E}_{t-1}\left(\mathbf{x}_{t} \mid \mathbf{z}_{t}\right)$. It can be shown ${ }^{12}$ that this conditional expectation is in fact an optimal estimation, in a mean square error sense, and corresponds to Equation (16). The Kalman filter is thus a particular type of Bayesian estimation.

Another useful characteristic of the Kalman filter is that it provides consistent model parameters estimates $\hat{\psi}$, when maximizing the log-likelihood function of error innovations:

$$
\log L(\boldsymbol{\psi})=-\frac{1}{2} \sum_{t} \log \left|\mathbf{F}_{t}\right|-\frac{1}{2} \sum_{t} \mathbf{v}_{t}{ }^{\prime} \mathbf{F}_{t}^{-1} \mathbf{v}_{t}
$$

where $\psi$ represents a vector containing the unknown parameters.

Moreover, the covariance matrix of the estimation errors, $\mathbf{I}(\hat{\psi})^{-1}$, may be obtained from the information matrix $\mathbf{I}(\psi)$ :

$$
\mathbf{I}(\psi)=\frac{\partial^{2} \log L(\psi)}{\partial \psi \partial \psi^{\prime}}
$$

\subsection{Kalman Filter Applied to Incomplete Panel-Data}

As already stated, existent literature stresses the use of the Kalman filter methodology with complete panel-data sets, which may induce information loss. However, it is not necessary to assume a fixed number of observable variables at each time in order to apply the Kalman filter.

Let $m_{t}$ be the number of observations available at time $t$, which needs not to be equal to the number of observations available at any other date. This means that the number of observations available at any date is time dependent. The measurement equation is again:

\footnotetext{
${ }^{12}$ See for example Øksendal (1998).
} 


$$
\mathbf{z}_{t}=\mathbf{H}_{t} \mathbf{x}_{t}+\mathbf{d}_{t}+\mathbf{v}_{t} \quad \mathbf{v}_{t} \sim N\left(\mathbf{0}, \mathbf{R}_{t}\right)
$$

but now $\mathbf{z}_{t}$ is a $m_{t} \times 1$ vector, $\mathbf{H}_{t}$ is a $m_{t} \times n$ matrix, $\mathbf{x}_{t}$ is a $n \times 1$ vector, $\mathbf{d}_{t}$ is a $m_{t} \times 1$ vector and $\mathbf{v}_{t}$ is a $m_{t} \times 1$ vector of serially uncorrelated Gaussian disturbances with mean $\mathbf{0}$ and covariance matrix $\mathbf{R}_{t}$ with dimension is $m_{t} \times m_{t}$. Under this assumptions, $\left\{\mathbf{z}_{t}\right\}_{t=1}^{T_{N}}$ will be considered an incomplete panel-data set.

To see why the Kalman filter still may be used with incomplete paneldata sets, note that given a vector of state variables $\hat{\mathbf{x}}_{t-1}$ and a covariance matrix $\mathbf{P}_{t-1}$ of the estimation errors, the filter first calculates a prediction of the state variables $\hat{\mathbf{x}}_{t \mid t-1}$ and of the covariance matrix $\mathbf{P}_{t \mid t-1}$ of the errors using equations (14) and (15).

For this calculations only the dynamic properties of the state variables are used which do not depend on the number of observable variables.

The filter then incorporates the new information given by the vector of observable variables $\mathbf{z}_{t}$. The same equations (16) and (17) can then be used to calculate optimal estimates of the state vector $\hat{\mathbf{x}}_{t}$ and of the covariance matrix $\mathbf{P}_{t}$. As mentioned before, since the Kalman filter computes at every date the conditional expectation $\hat{\mathbf{x}}_{t}=\mathrm{E}_{t-1}\left(\mathbf{x}_{t} \mid \mathbf{z}_{t}\right)$, the estimates can still be computed, even if the number of observations vary with time. Of course, the greater the number of observations available to update the filter, the better the accuracy of the estimation. This is reflected in a lower variance of the estimation error.

When a reduced number of observations is available at some date, the estimation error and its variance will be greater, reflecting more uncertainty on the true value of the state variables. In any case, the estimation of the state variables takes into account the whole variance-covariance structure among observations.

\subsection{Kalman Filter with a Nonlinear Measurement Equation}

When applying the Kalman filter to coupon-bond yields (or prices), we usually obtain a nonlinear measurement equation. In this case the extended Kalman 
filter, which applies to nonlinear measurement and/or transition equations, must be used. We will briefly ${ }^{13}$ describe the mathematics of the extended Kalman filter.

Since under the generalized Vasicek model, which is been used to illustrate the methodology, the transition equation is a linear function of the state variables, we are going to restrict the analysis to the case where only the measurement equation is a nonlinear function of the state variables ${ }^{14}$.

Let the measurement equation be a nonlinear function of state variables:

$$
\mathbf{z}_{t}=\mathbf{f}_{t}\left(\mathbf{x}_{t}\right)+\mathbf{v}_{t} \quad \mathbf{v}_{t} \sim N\left(\mathbf{0}, \mathbf{R}_{t}\right)
$$

with $\mathbf{f}_{t}: \mathbb{R}^{n} \rightarrow \mathbb{R}^{m_{t}}$ a continuous and differentiable function ${ }^{15}$.

The extended Kalman filter, when only the measurement equation is nonlinear, is obtained by linearizing $\mathbf{f}_{t}\left(\mathbf{x}_{t}\right)$ around the conditional mean $\hat{\mathbf{x}}_{t \mid t-1}$ :

$$
\mathbf{f}_{t}\left(\mathbf{x}_{t}\right)=\mathbf{f}_{t}\left(\hat{\mathbf{x}}_{t \mid t-1}\right)+\overline{\mathbf{H}}_{t}\left(\mathbf{x}_{t}-\hat{\mathbf{x}}_{t \mid t-1}\right)
$$

where $\overline{\mathbf{H}}_{t}=\left.\frac{\partial}{\partial \mathbf{x}_{t}^{\prime}} \mathbf{f}_{t}\left(\mathbf{x}_{t}\right)\right|_{\mathbf{x}_{t}=\hat{\mathbf{x}}_{|l|-1}}$.

The prediction step equations are the same as before. The update step equation under the extended Kalman filter is then:

$$
\begin{aligned}
& \hat{\mathbf{x}}_{t}=\hat{\mathbf{x}}_{t t-1}+\mathbf{P}_{t t-1} \overline{\mathbf{H}}_{t}^{\prime} \mathbf{F}_{t}^{-1} \mathbf{v}_{t} \\
& \mathbf{P}_{t}=\mathbf{P}_{t t-1}-\mathbf{P}_{t t-1} \overline{\mathbf{H}}_{t}^{\prime} \mathbf{F}_{t}^{-1} \overline{\mathbf{H}}_{t} \mathbf{P}_{t \mid t-1}
\end{aligned}
$$

${ }^{13}$ Additional information can be found in Harvey (1989).

${ }^{14}$ For example, under a CIR model, the resulting transition equation is also nonlinear. See Lund (1994, 1997), Duan and Simonato (1995), and Geyer and Pichler (1998).

${ }^{15}$ In this analysis we assume the general case of an incomplete panel-data setting, hence the dimension of the function range depends on the number of observations available at time $t$. In a complete panel-data setting, this time dependence disappears. 
where

$$
\begin{aligned}
& \mathbf{F}_{t}=\overline{\mathbf{H}}_{t} \mathbf{P}_{t \mid t-1} \overline{\mathbf{H}}_{t}^{\prime}+\mathbf{R}_{t} \\
& \mathbf{v}_{t}=\mathbf{z}_{t}-\mathbf{f}_{t}\left(\hat{\mathbf{x}}_{t \mid t-1}\right)
\end{aligned}
$$

A detailed explanation on how to apply the extended Kalman filter to coupon-bond yields can be found in Appendix B.

\section{EMPIRICAL RESULTS}

To illustrate our methodology, we estimate a 3-factor generalized Vasicek model using Chilean government bond data ${ }^{16}$. The data used consists of inflation-protected bonds, the most liquid fixed-income instrument traded in Chile. Thus, we are modeling the behavior of real, as opposed to nominal, interest rates. The choice of the Vasicek model seems appropriate for modeling real rates which may become negative whenever the rate of inflation exceeds the nominal interest rate.

Given that most of the outstanding bonds trade only sporadically, the Chilean government bond market can be characterized as a low-frequency transaction market and may be used to test our term-structure estimation methodology.

In the next sections we analyze the estimation results based on in-sample and out-of-sample yield errors and on the ability of the model to fit the observed term-structure of volatilities.

${ }^{16}$ These instruments are actually issued by the Chilean Central Bank, an institution equivalent to the Federal Reserve in the U.S. 


\subsection{Data description}

The data consists of all transactions at the Santiago Stock Exchange from January 1997 to December 2001 (1243 days) of pure-discount bonds and semiannual amortizing coupon bonds issued by the Chilean government. Pure-discount bonds are usually denominated PRBC ("Pagare Reajustable Banco Central") bonds, and semi-annual amortizing coupon bonds are called PRC ("Pagare Reajustable con Cupones") bonds. Both type of bonds are inflation-protected with payments brought to real terms using monthly inflation ${ }^{17}$.

Table 1 summarizes the data. It can be noted that pure-discount bonds have maturities of less than 1 year while coupon bonds have maturities ranging from 1 to 20 years. Trading frequency is defined as the number of days for which we have at least one transaction of a bond of a specific maturity over all available trading days. A trading frequency of $20 \%$ means that at least one bond with that maturity was traded an average of 50 days per year. From Table 1 we see that for most maturities, the trading frequency ranges from $30 \%$ to $45 \%$. Standard deviation of observed yields generally decreases as bond maturity increases, which is consistent with mean reversion in interest rates.

Figure 4 illustrates the sparseness or low frequency of daily bond transactions in Chile by showing for each day during the second semester of 2001 when a bond was traded or not. The panel-data shown is clearly incomplete, a condition that is essential to consider when choosing the estimation methodology. ${ }^{18}$

${ }^{17}$ In practice this is done by expressing payments in another unit, the UF ("Unidad de Fomento"), which is updated every month using the previous month inflation.

\footnotetext{
${ }^{18}$ Curiously, the figure resembles a DNA pattern.
} 
Table 1. Description of the data: Daily transactions of Chilean government inflationprotected pure discount and coupon bonds from January 1997 to December 2001.

\begin{tabular}{|c|c|c|c|c|}
\hline $\begin{array}{c}\text { Maturity } \\
\text { Range } \\
\text { (Years) }\end{array}$ & $\begin{array}{c}\text { Number of } \\
\text { Observations }\end{array}$ & $\begin{array}{c}\text { Average } \\
\text { Trading } \\
\text { Frequency }\end{array}$ & $\begin{array}{c}\text { Average } \\
\text { Yield }\end{array}$ & $\begin{array}{c}\text { Yield Standard } \\
\text { Deviation** }\end{array}$ \\
\hline \multicolumn{4}{|c|}{ Pure Discount Bonds } \\
\hline $0-1$ & 1115 & $89.70 \%$ & $5.81 \%$ & $2.04 \%$ \\
\hline \multicolumn{5}{|c|}{ Coupon Bonds } \\
\hline $1-1.5$ & 377 & $30.33 \%$ & $6.46 \%$ & $1.83 \%$ \\
$1.5-2.5$ & 426 & $34.27 \%$ & $6.29 \%$ & $1.45 \%$ \\
$2.5-3.5$ & 443 & $35.64 \%$ & $6.20 \%$ & $1.17 \%$ \\
$3.5-4.5$ & 642 & $51.65 \%$ & $6.15 \%$ & $1.17 \%$ \\
$4.5-5.5$ & 519 & $41.75 \%$ & $6.36 \%$ & $1.12 \%$ \\
$5.5-6.5$ & 550 & $44.25 \%$ & $6.36 \%$ & $0.87 \%$ \\
$6.5-7.5$ & 766 & $61.63 \%$ & $6.33 \%$ & $0.91 \%$ \\
$7.5-8.5$ & 921 & $74.09 \%$ & $6.22 \%$ & $0.81 \%$ \\
$8.5-9.5$ & 451 & $36.28 \%$ & $6.31 \%$ & $0.80 \%$ \\
$9.5-10.5$ & 584 & $46.98 \%$ & $6.31 \%$ & $0.65 \%$ \\
$10.5-11.5$ & 268 & $21.56 \%$ & $6.30 \%$ & $0.72 \%$ \\
$11.5-12.5$ & 458 & $36.85 \%$ & $6.21 \%$ & $0.67 \%$ \\
$12.5-13.5$ & 262 & $21.08 \%$ & $6.20 \%$ & $0.64 \%$ \\
$13.5-14.5$ & 507 & $40.79 \%$ & $6.14 \%$ & $0.60 \%$ \\
$14.5-15.5$ & 269 & $21.64 \%$ & $6.10 \%$ & $0.71 \%$ \\
$15.5-16.5$ & 311 & $25.02 \%$ & $6.13 \%$ & $0.61 \%$ \\
$16.5-17.5$ & 269 & $21.64 \%$ & $6.18 \%$ & $0.60 \%$ \\
$17.5-18.5$ & 309 & $24.86 \%$ & $6.32 \%$ & $0.53 \%$ \\
$18.5-19.5$ & 404 & $32.50 \%$ & $6.32 \%$ & $0.53 \%$ \\
$19.5-20$ & 533 & $42.88 \%$ & $6.26 \%$ & $0.60 \%$ \\
\hline Total & 10384 & \multicolumn{3}{|c}{} \\
\hline
\end{tabular}

*Trading frequency is defined as the number of days for which there is a transaction of a given bond over all available trading days.

${ }^{* *}$ Continuous Compounding 
Bond Maturity (Years)

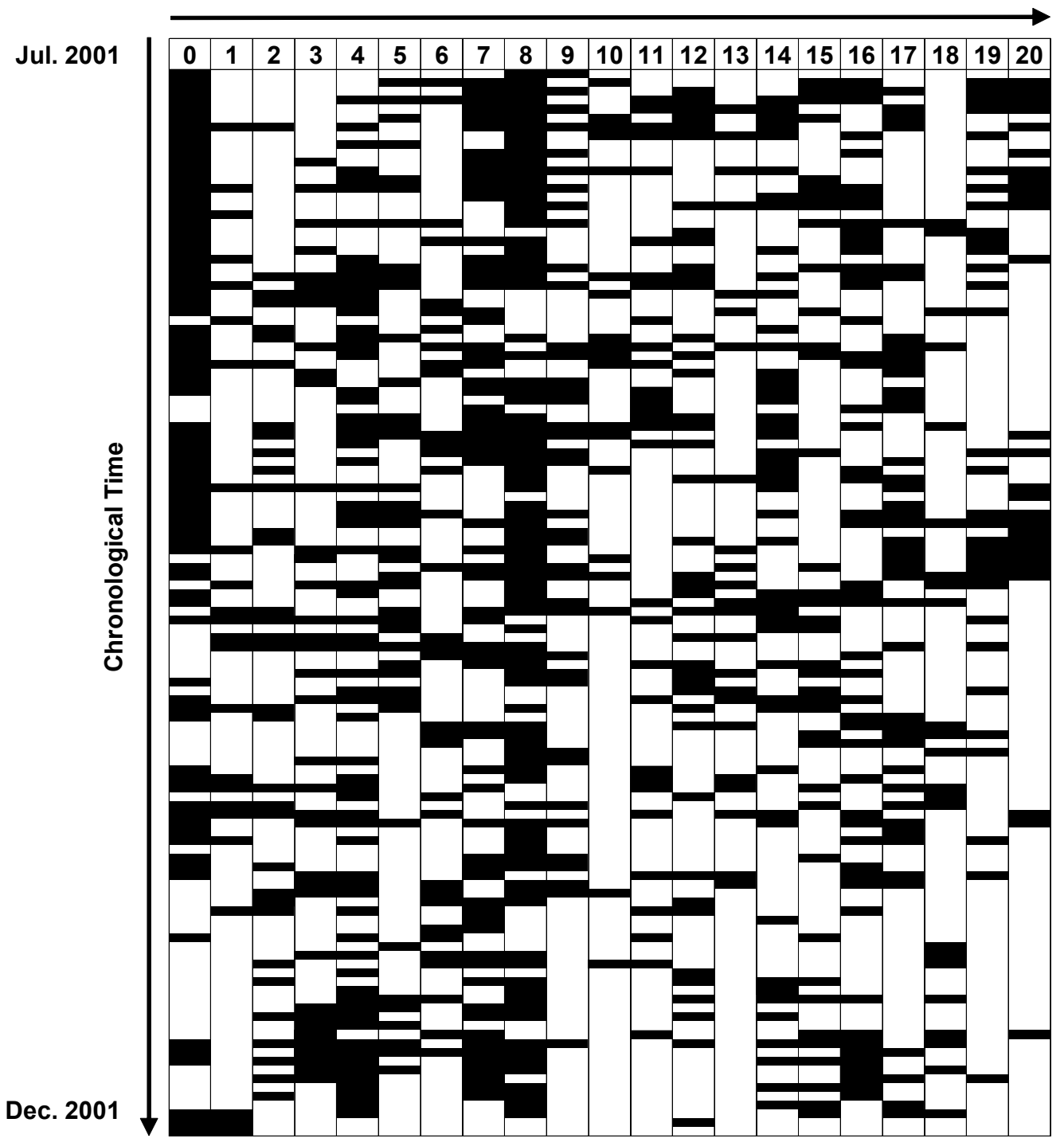

Fig. 4. Graphical description of available Chilean government inflation-protected discount and coupon bond daily data for the second semester of 2001. A black cell indicates that data was available for the corresponding maturity at a given day. 


\subsection{Estimation results}

We estimate the generalized Vasicek model parameters using bond price transactions data from January 1997 to December 2001. Since we are interested in extracting the term structure of interest rates, we use bond yields instead of bond prices.

As noted in section 4, the Kalman filter considers measurement errors in the observations. For simplicity we assume that the error variance-covariance matrix $\mathbf{R}_{t}$ is diagonal. Also, we aggregate bonds into 5 groups depending on their maturities: the first group includes the discount bonds with maturities up to 1 year, and the next 4 groups include coupon bonds with maturities from 1 to 5 years, from 6 to 10 years, from 11 to 15 years and from 16 to 20 years, respectively. Bonds within each group are assumed to have measurement errors with the same standard deviation: $\xi^{d}, \xi_{1}^{c}, \xi_{2}^{c}, \xi_{3}^{c}$ and $\xi_{4}^{c}$, respectively. With these assumptions 18 different parameters must be estimated ${ }^{19}$. Table 2 presents parameter estimates and their respective estimation errors. Note that all the parameters are statistically significant, though the mean reversion coefficient of the first factor is very small suggesting that this factor follows a process which is close to a random walk.

\footnotetext{
${ }^{19}$ Implementation issues of the model can be found in Appendix B.
} 
Table 2. Parameter estimates and standard errors from daily transactions of Chilean government inflation-protected pure discount and coupon bonds from January 1997 to December 2001.

\begin{tabular}{|l|l|l|}
\hline$\kappa_{1}$ & 0.00050 & 0.00012 \\
$\kappa_{2}$ & 1.11455 & 0.01681 \\
$\kappa_{3}$ & 2.16431 & 0.05362 \\
\hline$\sigma_{1}$ & 0.01747 & 0.00019 \\
$\sigma_{2}$ & 0.29298 & 0.00466 \\
$\sigma_{3}$ & 0.32780 & 0.00647 \\
\hline$\rho_{21}$ & 0.91042 & 0.01258 \\
$\rho_{31}$ & 0.84189 & 0.02376 \\
$\rho_{32}$ & 0.97121 & 0.00246 \\
\hline$\lambda_{1}$ & 0.00056 & 0.00002 \\
$\lambda_{2}$ & 0.01599 & 0.00418 \\
$\lambda_{3}$ & 0.05213 & 0.01836 \\
\hline$\delta$ & 0.05614 & 0.02654 \\
\hline$\xi^{d}$ & 0.00225 & 0.00014 \\
$\xi_{1}^{c}$ & 0.00225 & 0.00004 \\
$\xi_{2}^{c}$ & 0.00079 & 0.00001 \\
$\xi_{4}^{c}$ & 0.00027 & 0.00001 \\
\hline & & \\
\hline$\xi_{3}$ & & \\
\hline
\end{tabular}


One important measure of performance is the ability of the model to accurately fit observed prices, in particular for days with large number of transactions. Figure 5 shows the yield curve derived from the model for 01/09/1997. We see that the model is able to fit very well observed yields.

Another measure of performance is whether the model renders stable yield curves, in particular when there are missing observations. Figure 6 shows the yield curve obtained for 10/06/1999, the same day used in Figure 2 to illustrate the instability of the curve-fitting methods. We see that the estimated yield curve not only correctly fits observed yields for that day, but also is consistent with previous day observations. Note that the yield curve shown has been constructed using only prices for that particular day, and the dynamics of the interest rate process. We have not included the previous day curve in Figure 6 because it is very close to the curve shown. The model long-term yields for the current day, for which there are no data, are very close to the observed previous day long-term yields. This example illustrates that, for the same date shown in Figure 2, our method provides much more stable curves than those obtained by curve fitting methods.

Table 3 presents in-sample and out-of-sample error measures by maturity. Out-of-sample error measures were calculated by re-estimating the model using data from 1997-2000, and then comparing yield curves to observed yields for the year 2001, which was not used in the parameter estimation. It can be seen that all errors are reasonably low, while errors for short term bonds are larger than for long term bonds. Out-of-sample errors are similar to in-sample errors, showing the stability of the model and its ability to be used in real world applications. 


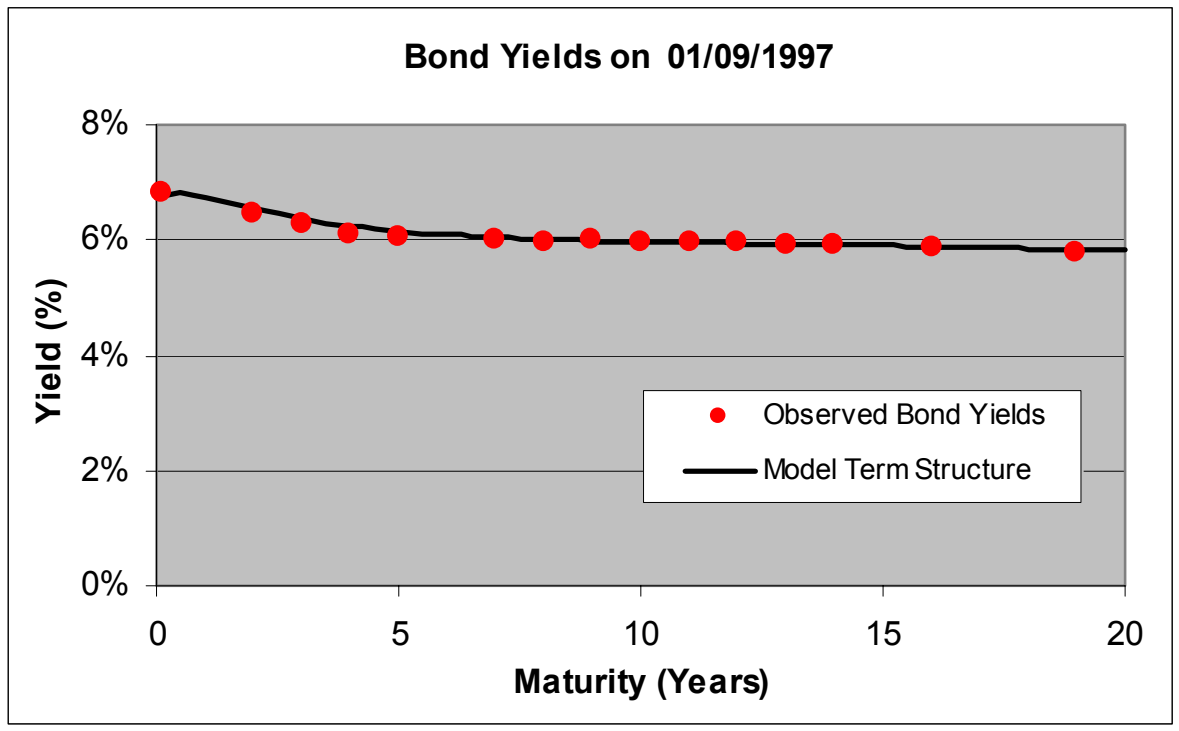

Fig. 5. Estimated and observed coupon bond yields on 01/09/1997.

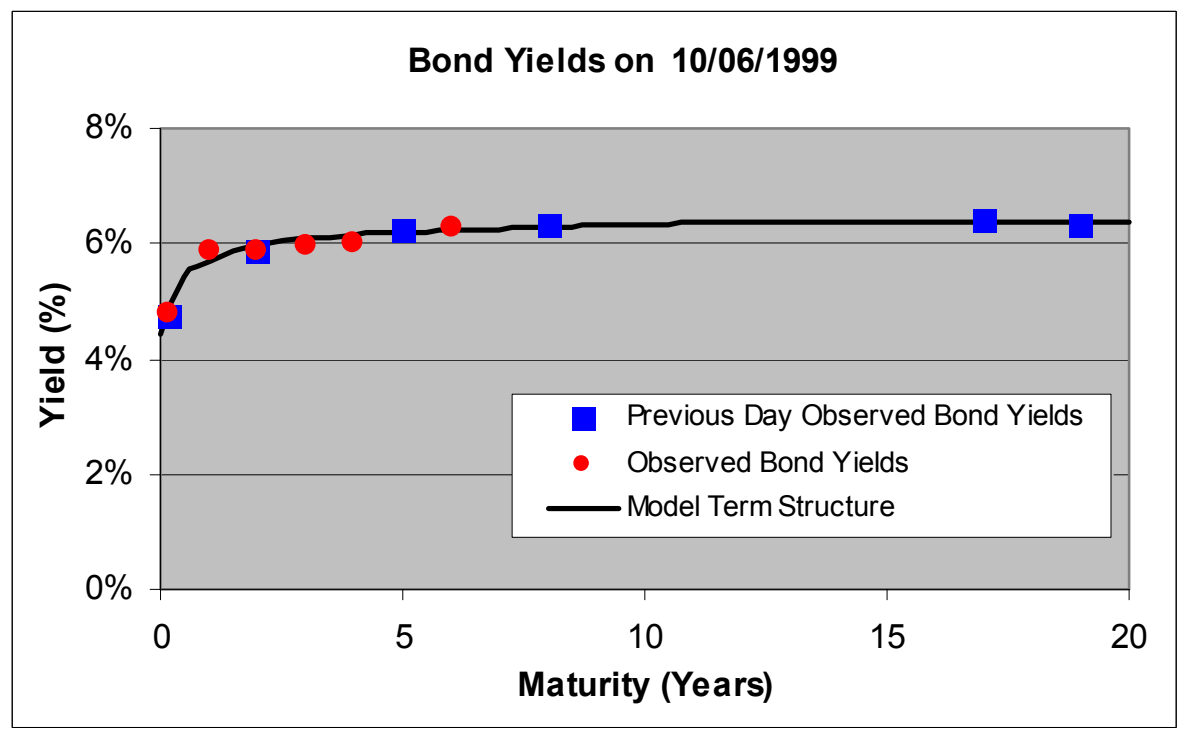

Fig. 6. Estimated and observed coupon bond yields on 10/06/1999. 
Table 3. In-Sample and Out-of-Sample RMSE for the Year 2001.

\begin{tabular}{|c|c|c|}
\hline $\begin{array}{c}\text { Maturity } \\
\text { Range } \\
\text { (Years) }\end{array}$ & $\begin{array}{c}\text { RMSE } \\
\text { In-Sample }\end{array}$ & $\begin{array}{c}\text { RMSE } \\
\text { Out-of- } \\
\text { Sample }\end{array}$ \\
\cline { 2 - 3 } & $\mathbf{2} 2001$ & $\mathbf{2 0 0 1}$ \\
\hline \multicolumn{3}{|c|}{ Discount Bonds } \\
\hline \multicolumn{3}{|c|}{ Coupon Bonds } \\
\hline $1-1.5$ & $0.25 \%$ & $0.33 \%$ \\
$1.5-2.5$ & $0.16 \%$ & $0.23 \%$ \\
$2.5-3.5$ & $0.17 \%$ & $0.21 \%$ \\
$3.5-4.5$ & $0.13 \%$ & $0.15 \%$ \\
$4.5-5.5$ & $0.16 \%$ & $0.16 \%$ \\
$5.5-6.5$ & $0.06 \%$ & $0.06 \%$ \\
$6.5-7.5$ & $0.05 \%$ & $0.06 \%$ \\
$7.5-8.5$ & $0.06 \%$ & $0.09 \%$ \\
$8.5-9.5$ & $0.06 \%$ & $0.08 \%$ \\
$9.5-10.5$ & $0.05 \%$ & $0.06 \%$ \\
$10.5-11.5$ & $0.04 \%$ & $0.04 \%$ \\
$11.5-12.5$ & $0.03 \%$ & $0.03 \%$ \\
$12.5-13.5$ & $0.03 \%$ & $0.03 \%$ \\
$13.5-14.5$ & $0.03 \%$ & $0.02 \%$ \\
$14.5-15.5$ & $0.02 \%$ & $0.02 \%$ \\
$15.5-16.5$ & $0.03 \%$ & $0.03 \%$ \\
$16.5-17.5$ & $0.03 \%$ & $0.03 \%$ \\
$17.5-18.5$ & $0.03 \%$ & $0.03 \%$ \\
$18.5-19.5$ & $0.03 \%$ & $0.04 \%$ \\
$19.5-20$ & $0.03 \%$ & $0.04 \%$ \\
\hline \multicolumn{3}{|c|}{ Total } \\
\hline $0-20$ & $0.10 \%$ & $0.11 \%$ \\
\hline \multicolumn{3}{|c|}{}
\end{tabular}


As a last measure of performance, we analyze the volatility structure of interest rates and compare it to volatilities obtained directly from bond yields. The theoretical volatility structure of interest rates, which is independent of the state variables, is obtained by applying Ito's lemma to Equation (8).

$$
\sigma_{R}(\tau)=\left(\sum_{i=1}^{N} \sum_{j=1}^{N} u_{i}(\tau) u_{j}(\tau) \sigma_{i} \sigma_{j} \rho_{i j}\right)^{1 / 2}
$$

where

$$
u_{i}(\tau)=-\frac{1-\exp \left(-k_{i} \tau\right)}{k_{i}}
$$

There are two difficulties in computing empirical estimates of the interest rate volatilities. First, most of the data consists of amortizing coupon bonds and we are interested in the volatility of spot rates. Second, the panel data contains many missing observations. To address these problems we aggregate the data in groups according to their maturity. The first group contains bonds with one to two years of maturity, and so on. Then, for each date we take the average yield of all the bonds in a given group and we compute the volatility of daily changes of these yields. In addition, we compute the average duration of the bonds in each group. To compare this empirical volatility to model spot volatilities, we assume that the volatility of each group represents the volatility of a discount bond with maturity equal to the average duration in the group.

Figure 7 shows the term structure of spot volatilities from the model and from the empirical estimates. Comparing this figure with Figure 3, we observe that our model volatilities are much closer to the empirical volatilities than those obtained using the curve fitting methods. 


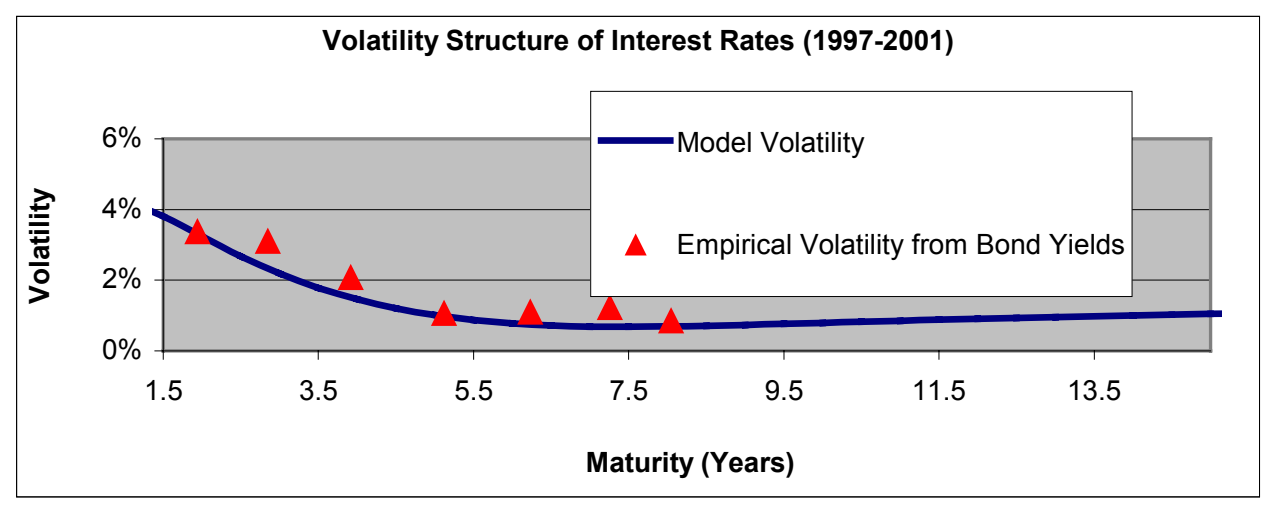

Fig. 7. Volatility Structure of Interest Rates 1997-2001.

\section{Conclusion}

The estimation of the term structure of interest rates is a critical issue, not only from a theoretical point of view, but also for all market participants including banks, regulators and financial institutions. It is an essential ingredient in the valuation and hedging of all fixed income securities. It is also necessary for financial planning and for implementing monetary policy. In economies with well developed and liquid financial markets, the existence of bond prices for a wide range of different maturities makes it easy to extract a term structure of spot rates that explains observed prices. Moreover, in some countries, such as the United States, zero-coupon bonds (Strips) of different maturities are individually traded. In many emerging markets, however, bonds trade infrequently so that for every particular day there are bond prices for only a few maturities. This missing-observation problem makes it difficult, and sometimes impossible, to estimate the term structure using only current data.

In this article we develop a methodology for using an incomplete paneldata of bond price observations to estimate the current term structure. We use an extended Kalman filter approach to estimate a dynamic multi-factor model of interest rates using the panel-data with missing observations. The Kalman filter estimation provides not only the parameters of the model but also the time series of the factors. 
The approach jointly estimates the current term structure and its dynamics. The model can be used to value and hedge all types of interest rate derivatives, including bonds with embedded options. This methodology also allows us to estimate the term structure for days with an arbitrary small number of traded bonds.

We implement the approach using a three factor generalized Vasicek (1977) model and Chilean government bond data. The methodology, however, can be implemented with a broad class of dynamic interest rate models and in any market with low frequency transactions, a very common situation in many emerging markets.

Our approach is currently being used by a consortium of financial and academic institutions in Chile to estimate the Chilean term structure of interest rates. The results are updated daily at the website RiskAmerica.com. 


\section{REFERENCES}

ANDERSEN, T.G. and J. LUND (1997) Estimating continuous time stochastic volatility models of the short term interest rate. Journal of Econometrics, Vol. 77, 343-377.

BABBS, S.H. and K.B. NOWMAN (1999) Kalman filtering of generalized Vasicek term structure models. Journal of Financial and Quantitative Analysis, Vol. 34, $\mathrm{N}^{\circ}$ $1,115-130$.

BALL, C. and W. TOROUS (1996) Unit roots and the estimation of interest rate dynamics. Journal of Empirical Finance, Vol. 3, 215-238.

BLISS, R.R. (1996) Testing term structure estimation methods. Advances in Futures and Operations Research, Vol. 9, 197-231.

BRENNAN, M.J., and E.S. SCHWARTZ (1979) A Continuous time approach to the pricing of bonds. Journal of Banking and Finance, Vol. 3, № 2, 133-155.

BRENNER, R.J., R.H. HARJES, and K.F. KRONER (1996) Another look at models of the short-term interest rate. Journal of Financial and Quantitative Analysis, Vol. 31, 85-107.

BROZE, L., O. SCAILLET and J.-M. ZAKOIAN (1995) Testing continuous time models of the short-term interest rate. Journal of Empirical Finance, Vol. 2, 199223.

CHAN, K.C., G.A. KAROLYI, F.A. LONGSTAFF and A.B. SANDERS (1992) Comparison models of the short-term interest rate. Journal of Finance, Vol. 47, 1209-1227.

CHEN, R.-R. and L. SCOTT (1993) Maximum likelihood estimation for a multifactor equilibrium model of the term structure of interest rates. Journal of Fixed Income, Vol. 3, 14-31.

CHEN, R.-R. and L. SCOTT (2003) Multi-factor Cox-Ingersoll-Ross models of the term structure: Estimates and tests from a Kalman filter model. Journal of Real Estate Finance and Economics, Forthcoming. 
CORTAZAR, G. and NARANJO, L. (2003) A multi-factor stochastic model and estimation procedure for the valuation and hedging of commodity contingent claims. Working Paper, Pontificia Universidad Catolica de Chile.

CORTAZAR, G. and SCHWARTZ, E.S. (2003) Implementing a Stochastic Model for Oil Futures Prices. Energy Economics, Forthcoming.

COX, J.C., J. INGERSOLL, and S. ROSS (1985) A theory of the term structure of interest rates. Econometrica, Vol. 53, 385-407.

DAI, Q. and K.J. SINGLETON (2000) Specification analysis of affine term structure models. Journal of Finance, Vol. 55, N 5, 1943-1978.

DE JONG, F. (2000) Time-series and cross-section information in affine term structure models. Journal of Business \& Economics Statistics, Vol. 18, № 3, 300314.

DE JONG, F. and P. SANTA-CLARA (1999) The dynamics of the forward interest rate curve: A formulation with state variables. Journal of Financial and Quantitative Analysis, Vol. 34, N 1, 131-157.

DEWACHTER, H. and K. MAES (2001) An admissible affine model for joint term structure dynamics of interest rates, Working Paper, Katholieke Universiteit Leuven.

DUAN, J.-C. and J.-G. SIMONATO (1995) Estimating and testing exponentialaffine term structure models by Kalman filter, Working Paper, CIRANO.

DUFFIE, D. and R. KAN (1996) A yield-factor model of interest rates. Mathematical Finance, Vol. 6, 379-406.

DUFFIE, D. and K.J. SINGLETON (1997) An econometric model of the term structure of interest-rate swap yields. Journal of Finance, Vol. 52, N 4, 1287-1321.

FISHER, M., D. NYCHKA, and D. ZERVOS (1994) Fitting the term structure of interest rates with smoothing splines, Working Paper, Federal Reserve Board of Governors. 
GEYER, A.L.J. and S. PICHLER (1998) A state-space approach to estimate and test multifactor Cox-Ingersoll-Ross models of the term structure, Working Paper, University of Economics Vienna.

HAMILTON, J.D. (1994) Time series analysis, Princeton University Press, Princeton, N.J.

HARVEY, A.C. (1989) Forecasting, structural time series models and the Kalman filter, Cambridge University Press, Cambridge.

HEATH, D., R. JARROW, and A. MORTON (1992) Bond pricing and the term structure of interest rates: A new methodology for contingent claims valuation. Econometrica, Vol. 60, 77-105.

HO, T.S.Y. and S. LEE (1986) Term structure movements and the pricing of interestrate contingent claims. Journal of Finance, Vol. 51, N 5, 1011-1029.

LANGETIEG, T.C. (1980) A multivariate model of the term structure. Journal of Finance, Vol. 35, № 1, 71-97.

LUND, J. (1994) Econometric analysis of continuous-time arbitrage-free models of the term structure of interest rates, Working Paper, The Aarhus School of Business.

LUND, J. (1997) Non-linear Kalman filtering techniques for term-structure models, Working Paper, The Aarhus School of Business.

MCCULOCH, J.H. (1971) Measuring the term structure of interest rates. Journal of Business, Vol. 44, N 1, 19-31.

MCCULOCH, J.H. (1975) The tax adjusted yield curve. Journal of Finance, Vol. 30, $\mathrm{N}^{\circ} 3,811-830$.

MOLINARE, A. (2002) Estructura y dinámica de tasas de interés reales en Chile: Información contenida en los pagarés reajustables con pagos en cupones del Banco Central, M.Sc. Thesis, Pontificia Universidad Católica de Chile.

NARANJO, L. (2002) Modelos lognormales de precios de commodities y calibración mediante el filtro de Kalman utilizando paneles de datos incompletos de cobre y petróleo. M.Sc. Thesis, Pontificia Universidad Católica de Chile 
NELSON, C.R. and A.F. SIEGEL (1987) Parsimonious modeling of yield curves. Journal of Business, Vol. 60, N 4, 473-489.

NOWMAN, K.B. (1997) Gaussian estimation of single-factor continuous time models of the term structure of interest rates. Journal of Finance, Vol. 52, 16951706.

NOWMAN, K.B. (1998) Continuous time short rate interest rate models. Applied Financial Economics, Vol. 8, 401-407.

ØKSENDAL, B. (1998) Stochastic differential equations : an introduction with applications. 5th ed., Springer, Berlin ; New York.

PEARSON, N.D. and T.-S. SUN (1994) Exploiting the conditional density in estimating the term structure: An application to the Cox, Ingersoll, and Ross model. Journal of Finance, Vol. 49, № 4, 1279-1304.

PENNACCHI, G.G. (1991) Identifying the dynamics of real interest rates and inflation: Evidence using survey data. Review of Financial Studies, Vol. 4, N 1, 5386.

SCHWARTZ, E.S. (1997) The stochastic behavior of commodity prices: Implications for valuation and hedging. Journal of Finance, Vol. 52, N³, 923-973.

SCHWARTZ, E.S. and J.E. SMITH (2000) Short-term variations and long-term dynamics in commodity prices. Management Science, Vol. 46, 893-911.

SØRENSEN, C. (2002) Modeling seasonality in agricultural commodity futures. Journal of Futures Markets, Vol. 22, 393-426.

SVENSSON, L.E.O. (1994) Estimating and interpreting forward interest rates: Sweeden 1992-1994, Working Paper, National Bureau of Economic Research.

VASICEK, O.A. (1977) An equilibrium characterization of the term structure. Journal of Financial Economics, Vol. 5, № 2, 177-188.

VASICEK, O.A. and H.G. FONG (1982) Term structure modeling using exponential splines. Journal of Finance, Vol. 37, N², 339-356. 


\section{APPENDIX A}

The Nelson and Siegel (1987) approach assumes that the forward rate curve is of the following form:

$$
f(T)=\beta_{0}+\beta_{1} e^{-\frac{T}{\tau_{1}}}+\beta_{2} \frac{T}{\tau_{1}} e^{-\frac{T}{\tau_{1}}}
$$

where $T$ is the time to maturity, and $\beta_{0}, \beta_{1}, \beta_{2}$ and $\tau_{1}>0$ are parameters.

The spot rates can then be calculated as the integral of forward rates:

$$
R(T)=\frac{1}{T} \int_{0}^{T} f(s) d s=\beta_{0}+\beta_{1}\left(1-e^{-\frac{T}{\tau}}\right) \frac{\tau}{T}+\beta_{2}\left(\left(1-e^{-\frac{T}{\tau}}\right) \frac{\tau}{T}-e^{-\frac{T}{\tau}}\right)
$$

Svensson (1994) proposes a generalization of Nelson and Siegel (1987) introducing a new term in the forward rate curve:

$$
f(T)=\beta_{0}+\beta_{1} e^{-\frac{T}{\tau_{1}}}+\beta_{2} \frac{T}{\tau_{1}} e^{-\frac{T}{\tau_{1}}}+\beta_{3} \frac{T}{\tau_{2}} e^{-\frac{T}{\tau_{2}}}
$$

where the new parameters are $\beta_{3}$ and $\tau_{2}>0$.

In both cases, coupon bond prices are calculated discounting each coupon at the corresponding spot rate. The parameters of the models can then be estimated by minimizing the quadratic errors in bond prices or yields.

\section{APPENDIX B}

In this appendix we describe in detail how to apply the methodology developed in Section 4 to the generalized Vasicek model introduced in Section 3, with an incomplete panel-data set of discount and coupon bond yields.

The transition equation of the state variables under a generalized Vasicek model is independent of the observations, and the associated terms appearing in equation (12) are: 


$$
\begin{aligned}
& \mathbf{A}_{t}=\operatorname{diag}_{n}\left(1-k_{i} \Delta t\right) \quad \mathbf{c}_{t}=\left(\begin{array}{c}
-\lambda_{1} \Delta t \\
\vdots \\
-\lambda_{n} \Delta t
\end{array}\right) \\
& \mathbf{Q}_{t}=\left(\begin{array}{ccc}
\sigma_{1}^{2} & \cdots & \sigma_{1} \sigma_{n} \rho_{1 n} \\
\vdots & \ddots & \vdots \\
\sigma_{n} \sigma_{1} \rho_{n 1} & \cdots & \sigma_{n}^{2}
\end{array}\right) \Delta t
\end{aligned}
$$

where $\operatorname{diag}_{n}\left(x_{i}\right)$ stands for a diagonal $n \times n$ matrix whose $(i, i)$ element is $x_{i}, \Delta t$ is the time interval at which yields are observed, and other parameters are the ones appearing in equation (4).

Let $m_{t}^{d}$ and $m_{t}^{c}$ be the number at time $t$ of observed discount and coupon bonds respectively and $\left\{\tau_{i, t}^{d}\right\}_{i=1}^{n_{t}^{d}}$ and $\left\{\tau_{i, t}^{c}\right\}_{i=1}^{n_{t}^{c}}$ the sets containing their respective associated maturities. The vector of observations $\mathbf{z}_{t}$ is then:

$$
\mathbf{z}_{t}=\left(\begin{array}{c}
\mathbf{z}_{t}^{d} \\
\mathbf{z}_{t}^{c}
\end{array}\right)
$$

where $\mathbf{z}_{t}^{d}$ and $\mathbf{z}_{t}^{c}$ are $m_{t}^{d} \times 1$ and $m_{t}^{c} \times 1$ vectors containing the observed yields of discount and coupon bonds respectively. Of course, either $m_{t}^{d}$ or $m_{t}^{c}$ can be zero, but not both at the same time.

The parameters of the measurement equation are:

$$
\mathbf{H}_{t}=\left(\begin{array}{c}
\mathbf{H}_{t}^{d} \\
\mathbf{H}_{t}^{c}
\end{array}\right) \quad \mathbf{d}_{t}=\left(\begin{array}{c}
\mathbf{d}_{t}^{d} \\
\mathbf{d}_{t}^{c}
\end{array}\right)
$$

where

$$
\mathbf{H}_{t}^{d}=\left(\begin{array}{c}
-\frac{\mathbf{u}\left(\tau_{1, t}^{d}\right)^{\prime}}{\tau_{1, t}^{d}} \\
\vdots \\
-\frac{\mathbf{u}\left(\tau_{m_{t}^{d}, t}^{d}\right)^{\prime}}{\tau_{m_{t}^{d}, t}^{d}}
\end{array}\right) \quad \mathbf{H}_{t}^{d}=\left(\begin{array}{c}
\frac{\partial}{\partial \mathbf{x}^{\prime}} y\left(\hat{\mathbf{x}}_{t \mid t-1}, \tau_{1, t}^{d}\right) \\
\vdots \\
\frac{\partial}{\partial \mathbf{x}^{\prime}} y\left(\hat{\mathbf{x}}_{t \mid t-1}, \tau_{m_{t}^{d}, t}^{d}\right)
\end{array}\right)
$$




$$
\mathbf{d}_{t}^{d}=\left(\begin{array}{c}
-v\left(\tau_{1, t}^{d}\right) \\
\vdots \\
-v\left(\tau_{m_{t}^{d}, t}^{d}\right)
\end{array}\right) \quad \mathbf{d}_{t}^{c}=\left(\begin{array}{c}
y\left(\hat{\mathbf{x}}_{t \mid t-1}, \tau_{1, t}^{c}\right)-\left(\frac{\partial}{\partial \mathbf{x}^{\prime}} y\left(\hat{\mathbf{x}}_{t \mid t-1}, \tau_{1, t}^{c}\right)\right) \hat{\mathbf{x}}_{t \mid t-1} \\
\vdots \\
y\left(\hat{\mathbf{x}}_{t \mid t-1}, \tau_{m_{t}^{c}, t}^{c}\right)-\left(\frac{\partial}{\partial \mathbf{x}^{\prime}} y\left(\hat{\mathbf{x}}_{t \mid t-1}, \tau_{m_{t}^{c}, t}^{c}\right)\right) \hat{\mathbf{x}}_{t \mid t-1}
\end{array}\right)
$$

The gradient of the yield with respect state variables can be computed by differentiating implicitly equation (10) with respect the state variables:

$$
\begin{aligned}
\frac{\partial}{\partial \mathbf{x}}\left(\sum_{j=1}^{M} \exp \left(\mathbf{u}\left(\tau_{j}\right)^{T} \mathbf{x}+v\left(\tau_{j}\right)\right)\right) & =\frac{\partial}{\partial \mathbf{x}}\left(\sum_{j=1}^{M} \exp \left(-y(\mathbf{x}, \tau) \tau_{j}\right)\right) \\
& =\frac{\partial}{\partial y}\left(\sum_{j=1}^{M} \exp \left(-y(\mathbf{x}, \tau) \tau_{j}\right)\right) \frac{\partial y(\mathbf{x}, \tau)}{\partial \mathbf{x}}
\end{aligned}
$$

so that:

$$
\frac{\partial y(\mathbf{x}, \tau)}{\partial \mathbf{x}}=\frac{\sum_{j=1}^{M} \mathbf{u}\left(\tau_{j}\right) \exp \left(\mathbf{u}\left(\tau_{j}\right)^{T} \mathbf{x}+v\left(\tau_{j}\right)\right)}{\sum_{j=1}^{M}-\tau_{j} \exp \left(-y(\mathbf{x}, \tau) \tau_{j}\right)}
$$

The remaining parameters to be specified belong to the covariance matrix of measurement errors. For this paper, we assume that this covariance matrix is diagonal and can only have 5 different parameters: $\xi^{d}, \xi_{1}^{c}, \xi_{2}^{c}, \xi_{3}^{c}$ and $\xi_{4}^{c}$. The first of them corresponds to the variance of measurement errors of discount bonds. The other 4 parameters correspond to the variance of coupon bonds for maturities ranging between 1 to 5 years, 6 to 10 years, 11 to 15 years and 16 to 20 years respectively.

$$
\mathbf{R}_{t}=\left(\begin{array}{cc}
\mathbf{R}_{t}^{d} & \mathbf{0} \\
\mathbf{0} & \mathbf{R}_{t}^{c}
\end{array}\right)
$$

where $\mathbf{R}_{t}^{d}=\operatorname{diag}_{n_{t}^{d}}\left(\xi^{d}\right)$ and $\mathbf{R}_{t}^{c}=\operatorname{diag}_{n_{t}^{c}}\left(\xi_{j}^{c}\right)$. 